Original article

\title{
Modeling of arterial hypertension's risk in occupational groups
}

\author{
Sergey A. Maksimov, Galina V. Artamonova
}

Research Institute for Complex Issues of Cardiovascular Diseases, Siberian Branch of Russian Academy of Medical Sciences, Kemerovo, Russia

Received 12 December 2012, Revised 19 December 2012, Accepted 12 January 2013.

(C) 2012, Maksimov S.A., Artamonova G.V.

(C) 2012, Russian Open Medical Journal

\begin{abstract}
Aim - Evaluate the influence of work environment on the risk of arterial hypertension (AH) development in employees of various social groups. Material and Methods - 3664 employees of Siberian industrial enterprises and office workers were examined. Apart from occupation AH predictors were considered to be gender, age, Quetlet index, smoking, alcohol abuse, marital status and education. Classification trees were used as a method of predicting AH presence or absence. Results - A classification tree allowing $75 \%$ prediction of $\mathrm{AH}$ presence/ absence was obtained. Quetlet index (100), age (83) and occupation (63) were maximum significant predictors for classification. A structure of the classification tree changed in different age groups and; moreover, with similar prediction level the predictor significance differed greatly. In middle-aged population occupation along with Quetlet index was characterized by higher significance (89) while in elderly subjects the significance of occupation decreased (55) and the significance of education and marital status rose (60 and 34, respectively). Different AH prevalence was observed in the occupational groups with similar working conditions. Conclusion - Quetlet index, age and occupation are highly significant for AH prediction in working age population. Occupation is very significant for $\mathrm{AH}$ prediction in middle-aged patients. Other factors under study do not usually influence AH development much, though, with ageing their role gets more important.
\end{abstract}

Keywords: occupational health, arterial hypertension, modelling

Cite as Maksimov SA, Artamonova GV. Modeling of arterial hypertension's risk in occupational groups. Russian Open Medical Journal 2013; 2: 0104.

Correspondence to Dr Sergey A. Maksimov. Address: Appt. 5, 9, Molodezhnaya str., Lesnaya Polyana, Kemerovo, 650071, Russia. Home phone: $+7(3842) 346090$. Mobile phone: +79045708245 . Fax: +7(3842)341902. E-mail: m1979sa@yandex.ru

\section{Introduction}

High medical, demographic and social significance of arterial hypertension $(\mathrm{AH})$ determines the relevance of studying various reasons for different prevalence of the disease in the population. There can be many reasons for $\mathrm{AH}$ development and this predetermines the need for defining and evaluating its predictors in order to achieve better prevention, diagnosis and treatment. Most researchers think that $\mathrm{AH}$ is a multigenic and multifactorial disease resulting from both hereditary factors and various social, occupational, physical or ecological exposures [1-3].

Occupation as one of the risk factors for $\mathrm{AH}$ development has been reported in many studies [4-7]. It should be noted that occupation is not only a combination of physical, biological and chemical exposures at a workplace, work difficulty and strain but also a multicomponent system largely determining various aspects of a person's life activities. Social importance of work doesn't raise any doubts and it predetermines a whole range of AH risk factors, e.g. social status, education, intelligence, living standards, the level of social adaptation, etc. The association of occupation and way of life components, such as physical activity, dietary and social habits, etc., has been actively discussed. Besides, as it has been stated above, an individual spends most of his working lifetime being exposed to a combination of occupational factors (often high levels of exposure) and certain work difficulty and strain, which depend on the type of occupation.

A significant role of occupation in forming many aspects of a person's living environment, which can increase the risk of $A H$, describes the occupation not only as one of $\mathrm{AH}$ risk factors but also as an important complex part of the system of risk factors. The complexity and interrelatedness of this system leads to the need for its studying with multivariate statistical methods allowing describing complex structures and taking into account the association between factors.

The study is aimed at evaluating the influence of work environment on the risk of arterial hypertension in employees of various social groups.

\section{Material and Methods}

3664 employees of Siberian industrial enterprises and public or private companies chosen by random sampling were surveyed and examined in order to achieve the aim of the study. If there were enough people of the same occupation they were grouped accordingly while occupations represented in small numbers were grouped based on the type of work, occupational hazards, work difficulty and strain.

18 occupational groups were formed: 
- School teachers (285 people),

- Mid-level and top executives (203),

- Finance workers (accountants) (60),

- Engineering technicians (214),

- Coal-mine supervisors (284),

- Car drivers (87),

- Operators and dispatch clerks (154),

- People of physically non-demanding jobs (150),

- Electricians (117),

- Coal-mine equipment engine-drivers (230),

- Large-scale equipment drivers (incl. dump trucks) (181),

- Special equipment drivers (bulldozers, excavating machinery, etc.) (413),

- Locksmiths (234),

- People of physically-demanding jobs (210),

- Coal-mine face workers (147),

- Coal-mine shaftmen (260),

- Coal-mine wiremen (234),

- Coal-mine support workers (181).

$73.4 \%$ of the studied population were men and $26.6 \%$ were women with the proportion of men to women being significantly different depending on the occupational group. The mean age was $42.2 \pm 9.9$ years, ranging from 19 to 75 years. The age pattern was as follows: people under 41 years old made up $39.6 \%$, people aged 41-50 years made up $39.1 \%$ and people over 51 were $21.3 \%$.

The guidelines stated below were applicable when subjects were surveyed and examined. Subjects surveyed were considered to have a family if they permanently lived together with their partner irrespective of being married. Subjects were considered to smoke if they had at least 1 cigarette a day and former smokers were classified as non-smokers; subjects who evaluated their drinking habit as "moderate" or "excessive" constituted a group of alcohol abuse.

According to the education level those asked were divided into 3 groups: people with higher education (having graduated from university or institute), vocational secondary education (vocational training college or trade school) and secondary-level education (general high school or specialized high school). The latter also included those subjects who did not finish their secondary education.

The height and weight of the subjects were measured according to the standard techniques and Quetelet index was measured as follows: Quetelet index=weight $(\mathrm{kg}) /$ height $\left(\mathrm{m}^{2}\right)$.

Blood pressure was taken according to the standard World Health Organization/International Society of Hypertension technique (1999). The subjects were diagnosed with arterial hypertension if they had a systolic pressure of $\geq 140 \mathrm{mmHg}$ and a diastolic pressure of $\geq 90 \mathrm{mmHg}$ or if they were taking antihypertensive drugs during the examination.

The examination and surveying was conducted according to the principles of the Ethics Committee of the Research Institute for Complex Issues of Cardiovascular Diseases, designed in accordance with the Declaration of Helsinki on the ethical principles for medical research involving humans. All the subjects signed an informed consent to take part in the study.

\section{Statistics}

Quantitative variables were described as means and standard deviation and descriptive variables as percentages. Pearson's chisquare $\left(\chi^{2}\right)$ test was used to analyze contingency tables. The normality of distribution was obtained by Shapiro-Wilk test, Levene's test was used to assess the equality of variances. If all the conditions were observed Student's t-test was used to assess intergroup differences and, if not, Mann-Whitney test was used.

Classification trees were used as a method of $\mathrm{AH}$ presence/absence predicting. The method allows predicting membership of cases or objects in the classes of a categorical dependent variable from their measurements on one or more independent (predictor) variables. Discriminant-based univariate splits for categorized and ordered predictors were used. The criteria for predictive accuracy were equal misclassification costs and prior probabilities estimated by the class proportions of the sample. To prune on misclassification error was chosen as a stopping rule, with the minimum number of misclassified objects being considered equal 10 and the standard error 1.0. The optimality of the obtained classification tree was assessed by vfold cross validation with the number of random samples being equal 3. The critical level of statistical significance was considered to be $95 \%$ and a statistically significant $p$-value was considered to be $<0.05$.

\section{Results}

A classification tree for $\mathrm{AH}$ presence/absence with 6 splits and 7 terminal nodes was obtained (Figure 1). At different split levels the criteria for being classified as having $\mathrm{AH}$ were middle and old age, high Quetlet index, low education level and occupation. In particular, people over 41.18 years old, who were classified as hypothetically having $\mathrm{AH}$, were further classified according to their occupational group. Additionally, 2 terminal nodes were also formed depending on the affiliation with a certain occupational group. Teachers, executives, accountants, engineering technicians, car drivers, operators, electricians, coal-mine equipment enginedrivers, large-scale and special equipment drivers and physicallydemanding jobs were classified as occupations predetermining $\mathrm{AH}$ development.

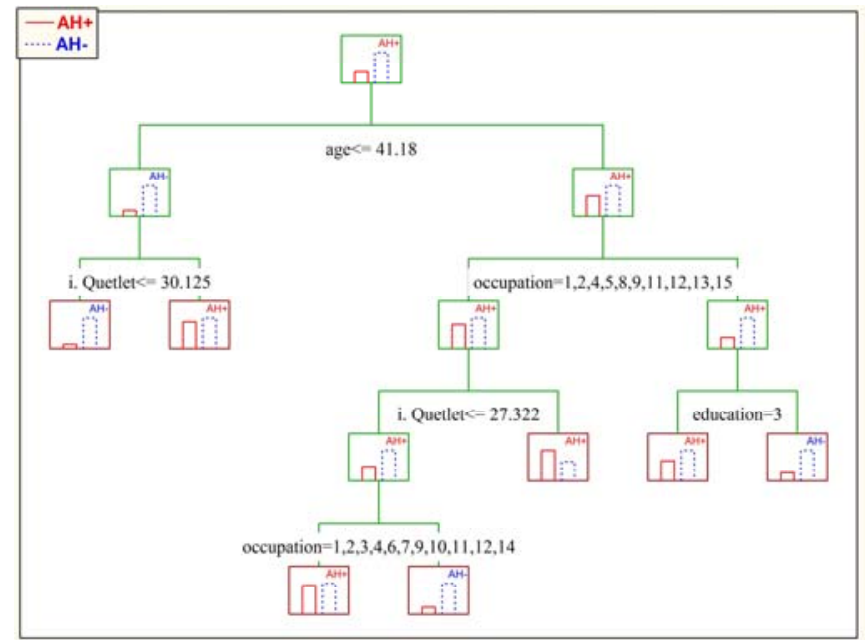

Figure 1. Arterial hypertension presence/absence classification tree

Occupational group number is consistent with its number in Material and Method section. Education 3 means secondary education. 


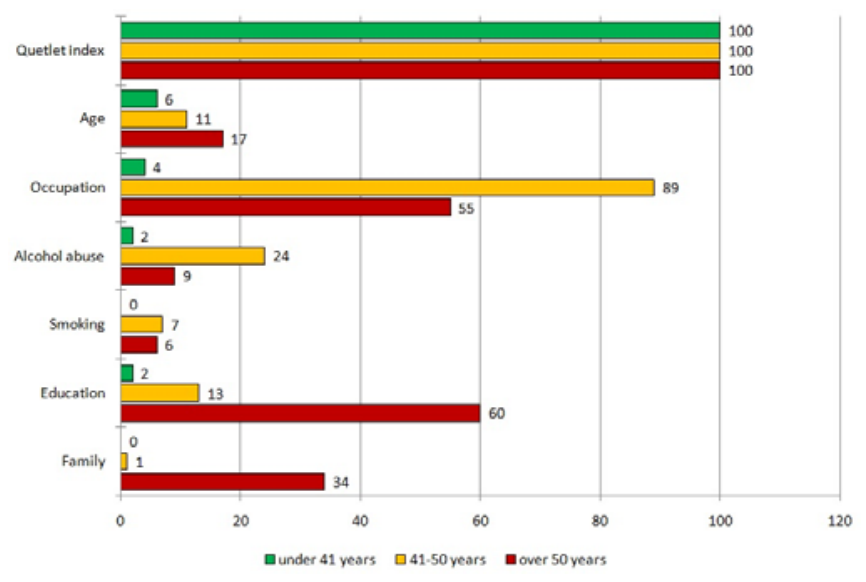

Figure 2. Predictor significance (scores) in different age groups

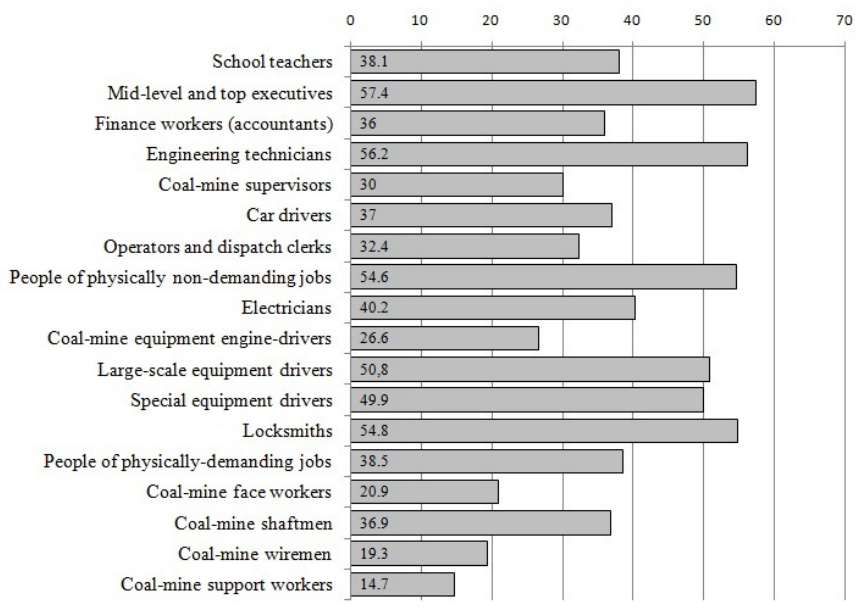

Figure 3. Arterial hypertension incidence, $\%$, in different occupational groups

Table. Risk factor-related arterial hypertension incidence in the working population

\begin{tabular}{|c|c|c|c|c|c|c|}
\hline \multicolumn{2}{|c|}{ Factors } & \multirow{3}{*}{$\begin{array}{c}\mathrm{N} \\
2485 \\
746\end{array}$} & \multirow{3}{*}{$\begin{array}{c}\mathrm{AH} \\
37.6 \\
44.8 \\
\end{array}$} & \multirow{3}{*}{$\begin{array}{c}\text { No } \\
\text { AH } \\
62.4 \\
55.2 \\
\end{array}$} & \multirow{3}{*}{$\begin{array}{c}\begin{array}{c}\chi^{2} / t- \\
\text { test }\end{array} \\
12.4\end{array}$} & \multirow{3}{*}{$\begin{array}{c}p \\
<0.01\end{array}$} \\
\hline Gender & Men & & & & & \\
\hline & Women & & & & & \\
\hline \multirow[t]{3}{*}{ Age } & $\mathrm{N}$ & - & 1258 & 1936 & \multirow{3}{*}{20.1} & \multirow{3}{*}{$<0.01$} \\
\hline & Mean & - & 46.1 & 39.3 & & \\
\hline & SD & - & 8.6 & 9.7 & & \\
\hline Quetlet & $\mathrm{N}$ & - & 792 & 1696 & \multirow{3}{*}{14.1} & \multirow{3}{*}{$<0.01$} \\
\hline \multirow[t]{2}{*}{ index } & Mean & - & 28.6 & 25.5 & & \\
\hline & SD & - & 4.8 & 5.1 & & \\
\hline \multirow{2}{*}{ Family } & Yes & 1424 & 28.2 & 71.8 & \multirow{2}{*}{4.8} & \multirow{2}{*}{$<0.05$} \\
\hline & No & 332 & 22.3 & 77.7 & & \\
\hline \multirow[t]{3}{*}{ Education } & Higher & 989 & 41.6 & 58.4 & \multirow{3}{*}{5.8} & \multirow{3}{*}{$>0.05$} \\
\hline & Trade school & 1610 & 37.1 & 62.9 & & \\
\hline & Secondary & 608 & 40.8 & 59.2 & & \\
\hline \multirow[t]{2}{*}{ Smoking } & Yes & 1596 & 34.7 & 65.3 & \multirow{2}{*}{24.3} & \multirow{2}{*}{$<0.01$} \\
\hline & No & 1611 & 56.8 & 43.2 & & \\
\hline \multirow{2}{*}{$\begin{array}{l}\text { Alcohol } \\
\text { abuse }\end{array}$} & Yes & 1815 & 29.2 & 70.8 & \multirow{2}{*}{0.8} & \multirow{2}{*}{$>0.05$} \\
\hline & No & 336 & 31.6 & 68.4 & & \\
\hline
\end{tabular}

The following predictors showed maximum rank significance for classification: Quetlet index -100 , age -83 , and occupation 63. Rank significance of other predictors was lower and made up 21 scores for education and 2-7 for smoking, gender, social status and alcohol abuse. The assessment of the proportion of observed and predicted objects showed that $\mathrm{AH}$ presence and absence had been correctly predicted by the classification tree method in $64.2 \%$ and $79.1 \%$ of cases, respectively, with the average accurate prediction making up $75.2 \%$. Further global cross-validation confirmed the prediction results: $\mathrm{AH}$ presence had been correctly predicted in $76.3 \%$ of cases and $\mathrm{AH}$ absence in $60.3 \%$ of cases, with the average accurate prediction making up $64.6 \%$. High percentage of inaccurately predicted $\mathrm{AH}$ presence/absence was related to the multifactorial nature of the disease.

In order to further evaluate the association of occupation and $\mathrm{AH}$ in terms of age and gender relations, classification trees for $\mathrm{AH}$ presence/absence in gender and age groups were made. No significant gender-related differences from the above mentioned classification tree were found, splitting conditions, the significance of main predictors and the prediction level being similar.

Age-related differences greatly altered the classification tree structure and with the similar prediction level in age groups the significance of classification predictors differed much (Figure 2). Young employees had only one highly significant predictor, Quetlet index (100), while the rank significance of other predictors was $0-6$. Middle-aged employees were characterized by high rank significance of occupation (89) along with Quetlet index; alcohol abuse significance is 24 and the significance of other predictors ranged from 1-13. Elderly patients still had highly significant Quetlet index while occupation significance was slightly lower (up to 55) and education (60) and marital status (34) significance was higher, the other predictor significance ranging from 6 to17. Of note, occupation had maximum rank significance in middle-aged adults, e.g. the life period when an intensive increase in $\mathrm{AH}$ incidence is normally observed [8-11]. If Quetlet index, which significance for $\mathrm{AH}$ presence/absence is always high, is not taken into account, occupation, related work conditions and the way of life are the factors predetermining $\mathrm{AH}$ development in the ageing population.

Such long established statistical methods as Pearson's chisquare test $\left(\chi^{2}\right)$ and Student's t-test confirmed the main $\mathrm{AH}$ predictors (Quetlet index, age, occupation) as being relevant. The occupational groups under study had significantly different proportion of $\mathrm{AH}$ patients $\left(\chi^{2}=239.7, p<0.01\right)$ (Figure 3 ). All the coal-miner groups (coal-mine supervisors, coal-mine equipment engine-drivers, coal-mine face workers or support workers), except for shaftmen, had low proportion (<35\%) of $\mathrm{AH}$ patients despite less favourable working conditions, including high work difficulty and strain, compared to all the other groups. This is due to pre-employment screening and regular medical check-ups as well as self-selection. Scientific medical reports also contain the data on such "healthy worker" phenomenon [12-14]. Except coalminers operators constitute a group with comparatively low proportion of $\mathrm{AH}$ patients.

High proportion of $\mathrm{AH}$ patients (>50\%) was observed in the groups who had different working conditions. White-collar workers, e.g. executives and engineering technicians, had $\mathrm{AH}$ in $57.4 \%$ and $56.2 \%$ of cases, respectively; $54.6 \%$ and $54.8 \%$ of employees having physically non-demanding jobs and fitters, respectively, were $\mathrm{AH}$ patients. High proportion of AH patients was seen in the group of special equipment drivers (49.9\%) and largescale equipment drivers (50.8\%) who were exposed to adverse factors and whose work was extremely difficult and intense. Such white-collar workers as teachers or accountants, car drivers, 
electricians, or fitters/employees having physically demanding jobs had moderate $\mathrm{AH}$ incidence (35-50\%).

The Table shows AH incidence according to other predictors (except occupation) as well as mean age and Quetlet index in $\mathrm{AH} /$ non-AH groups. Maximum differences were observed in age and Quetlet index-related $\mathrm{AH}$ incidence, with t-test being $20.1 \mathrm{n}$ 14.1, respectively. According to a classic interpretation of the relation of these factors to cardiovascular diseases, subjects with $\mathrm{AH}$ are characterized by higher mean age and Quetlet index $(p<0.05)$.

Gender, marital status and smoking-related differences in $\mathrm{AH}$ incidence were significant but less obvious than those related to Quetlet index, age or occupation. AH were more frequently diagnosed in women as well as in non-smokers and people having a family. Gender-related differences were due to special features of the studied sample which included high number of occupational groups comprising people of different sex and working conditions. Multifactorial analysis of variance confirmed that there were no gender-related differences in $\mathrm{AH}$ incidence in the occupational groups having the same proportion of men and women.

As for smoking and occupation-related factors significantly higher $\mathrm{AH}$ incidence was observed in non-smokers in a range of occupational groups, e.g. executives, car drivers, employees having physically non-demanding jobs, coal-mine equipment engine drivers and special equipment drivers. The other groups did not demonstrate any differences in $\mathrm{AH}$ incidence between smokers and non-smokers. Reports of other authors also evidence lower $\mathrm{AH}$ incidence in smokers than in non-smokers [15-17].

\section{Discussion}

The obtained classification tree demonstrates significant association of occupation with the probability of $\mathrm{AH}$ incidence, which is further confirmed by such long established statistical methods as Pearson's chi-square test $\left(\chi^{2}\right)$ and Student's t-test. Medical data on this topic are extensive; however, there are usually some gaps. The great majority of authors study the association of $\mathrm{AH}$ incidence with working conditions on 1-2, less often, several occupational groups $[7,18]$ with the working hypothesis being the impact of one or two workplace exposures (noise, vibration, microclimate, etc.) $[6,19]$ or working conditions (level of stress, work strain, etc.) $[5,16]$. The studies analyzing a vast number of occupations, normally, classify them according to the type of work being done: intellectual, manual of various difficulty or operator work $[8,20]$. Classification tree analysis allowed to evaluate the association of occupation and $\mathrm{AH}$ based on a significant number of occupational groups. This approach is very beneficial due to different $\mathrm{AH}$ incidence in the occupational groups having similar work type.

The obtained classification tree allows a $75 \%$ prediction of $\mathrm{AH}$ probability in the working population. Taking into account that there are many reasons for $\mathrm{AH}$ development and that the prediction is based on 7 predictors, only 3 of which are highly significant, the obtained prediction level can be considered very high. Undoubtedly, individual prediction requires higher predictive accuracy; however, the obtained results can be used in epidemiological estimates.

\section{Limitations}

In general, different $\mathrm{AH}$ incidence in similar work type and work exposure groups indicates that there are specific features in some occupational groups, such as a "healthy worker" effect [22] and, probably, professional traditions [23-24] and the specific conditions of entering an occupational group [25-26]. The goal and objectives of this paper do not allow detailed study of those aspects; however, there is no doubt that the conducted analysis demonstrates their significance and the need to take those aspects into account in further studies.

This work encompasses only 18 specific occupational groups which, of course, do not represent all the occupational groups of the working age population. However, it is worth noting that despite the groups were few the occupations under study represented almost all the spectrum of work activities: brain work, physical work, industry workers and civil servants; so the groups, significantly different in terms of the work intensity, difficulty and working conditions, were represented.

\section{Conclusion}

1) Quetlet index, age and occupation play a highly significant role in $\mathrm{AH}$ prediction in the working population. The obtained classification tree allows accurately predict $\mathrm{AH}$ presence/absence in $75.2 \%$ of people.

2) Work conditions are significant for $\mathrm{AH}$ prediction in middleaged population.

3) Gender, marital status, obsessive habits and education do not normally influence $\mathrm{AH}$ prediction much; however, they become more significant with ageing.

\section{Acknowledgments}

The research was financed by the Research Institute for Complex Issues of Cardiovascular Diseases, Russian Academy of Medical Sciences, Siberian Branch, and there is no financial interest to report. Authors express gratitude to the staff of Research Institute for Complex Issues of Cardiovascular Diseases RAMS SB, who has contributed to the study by making substantial contributions to acquisition of data: Ogarkov M.Yu., Skripchenko A.E., lankin M.Yu., Makarov S.A., Indukaeva E.V., Mulerova T.A., Shapovalova E.B.

Conflict of interest: none declared.

\section{Reference}

1. Martynov Al, Ostroumova OD, Zykova AA, Mamaev VI. Genetic aspects of essential arterial hypertension (summing up the 8th and 9th European Conferences on Arterial Hypertension). Clinical Medicine (Moscow) 2000; 12: 4-8. (PMID: 11210351) [Article in Russian]

2. Dzau VJ, Gibbons GH, Kobilka BK, Lawn RM, Pratt RE. Genetic models of human vascular disease. Circulation 1995; 2: 521-531. (PMID: 7805258)

3. Taylor JY, Sun YV, Hunt SC, Kardia SLR. Gene-environment interaction for hypertension among African American women across generations. Biol Res Nurs 2010; 12: 149-155. (doi: 10.1177/1099800410371225)

4. Tsutsumi A, Kayaba K, Tsutsumi K, Igarashi M. Association between job strain and prevalence of hypertension: a cross sectional analysis in a Japanese working population with a wide range of occupations: the Jichi Medical School cohort study. Occup Environ Med 2001; 6: 367373. (doi: 10.1136/oem.58.6.367)

5. Mills P, Davidson K, Farag N. Work stress and hypertension: a call from research into intervention. Ann Behav Med 2004; 1: 1-3. (doi: 10.1207/s15324796abm2801_1)

6. Tomei F, De Sio S, Tomao E, et al. Occupational exposure to noise and hypertension in pilots. International Journal of Environmental Health Research 2005; 2: 99-106. (doi: 10.1080/09603120500061534) 
7. Nakanishi N, Nakamura K, Ichikawa S, Suzuki K, Tatara K. Lifestyle and the development of hypertension: a 3-year follow-up study of middleaged Japanese male office workers. Occup Med (Lond) 1999; 49: 109114. (doi:10.1093/occmed/49.2.109)

8. Lee $D$, Chiu M, Manuel D, et al. Trends in risk factors for cardiovascular disease in Canada: temporal, socio-demographic and geographic factors. CMAJ 2009; 3-4: E55-E66. (doi: 10.1503/cmaj.081629)

9. Cutler JA, Sorlie PD, Wolz M, Thom T, Fields LE, Roccella EJ. Trends in hypertension prevalence, awareness, treatment, and control rates in United States adults between 1988-1994 and 1999-2004. Hypertension 2008; 52: 818-827. (doi: 10.1161/HYPERTENSIONAHA.108.113357)

10. Falaschetti E, Chaudhury M, Mindell J, Poulter N. Continued improvement in hypertension management in England: results from the Health Survey for England 2006. Hypertension 2009; 53: 480-486. (doi:10.1161/HYPERTENSIONAHA.108.125617)

11. Psaltopoulou T, Orfanos P, Naska A, Lenas D, Trichopoulos D, Trichopoulou A. Prevalence, awareness, treatment and control of hypertension in a general population sample of 26913 adults in the Greek EPIC study. Int J Epidemiol 2004; 33: 1345-1352. (doi: 10.1093/ije/dyh249)

12. Hannerz H, Tuchsen F, Spanqenberg S, Albertsen K. Industrial differences in disability retirement rates in Denmark, 1996-2000. Int J Occup Med Environ Health 2004; 4: 465-471. (PMID: 15852761)

13. Siebert U, Rothenbacher D, Daniel U, Brenner H. Demonstration of the healthy worker survivor effect in a cohort of workers in the construction industry. Occup Environ Med 2001; 58: 774-779. (doi: 10.1136/oem.58.12.774)

14. Burns CJ, Bodner KM, Jammer BL, Collins JJ, Swaen GMH. The healthy worker effect in US chemical industry workers. Occup Med (Lond) 2011; 61: 40-44. (doi: 10.1093/occmed/kqq168)

15. Erem C, Hacihasanoglu A, Kocak M, Deger O, Topbas M. Prevalence of prehypertension and hypertension and associated risk factors among Turkish adults: Trabzon hypertension study. J Public Health (Oxf) 2008; 1: 47-58. (doi: 10.1093/pubmed/fdn078)

16. Yang $H$, Schnall PL, Jauregui M, Su TC, Baker D. Work hours and selfreported hypertension among working people in California. $\begin{array}{llll}\text { Hypertension 2006; } & \text { 48: }\end{array}$ 10.1161/01.HYP.0000238327.41911.52).

17. Niskanen L, Laaksonen D, Nyyssonen $K$, et al. Inflammation, abdominal obesity, and smoking as predictors of hypertension. Hypertension 2004; 44: 859-865. (doi:10.1161/01.HYP.0000146691.51307.84)

18. Zinenko GM, Petrichenko SI, Miroshnikov MP, Dasaeva LA, Vermel' AE. Features of cardiologic diseases prevalence among individuals engaged into geology. Med Tr Prom Ekol 2005; 1: 8-14. (PMID: 15794503)

19. Pen'kovich AA, Kaliaganov PI. Arterial hypertension and ischemic heart disease in workers exposed to local vibration. Med Tr Prom Ekol 2005; 5: 32-35. (PMID: 15991716)

20. Greiner BA, Krause N, Ragland D, Fisher JM. Occupational stressor and hypertension: a multi-method study using observer-based job analysis and self-report in urban transit operators. Soc Sci Med 2004; 59: 10811094. (doi: 10.1016/j.socscimed.2003.12.006)

21. McMichael AJ. Standardized mortality ratios and the "healthy worker effect»: scratching beneath the surface. J Occup Med 1976; 18: 165168. (PMID: 1255276)

22. Reports to the Workers' Compensation Board on the Healthy Worker Effect. Toronto, Canada: Ministry of Labour of the Government of Ontario, ISDP Report No 3. 1988. URL: http://www.canoshweb.org/odp/html/JUL1988.htm (26 October 2012, date last accessed).

23. Bugajska J, Jedryka-Goral A, Widerszal-Bazyl $M$, et al. Job strain, overtime, life style, and cardiovascular risk in managers and physical workers. Int J Occup Saf Ergon 2011; 17: 25-32. (PMID: 21375951)

24. Zhuravleva KI, Titova IA. Life style and the health of workers. Sov Zdravookhr 1986; 11: 13-17. (PMID: 3810236) [Article in Russian]
25. Chapman BJ. Modelling occupational choice: non-pecuniary employment attributes and endogenous preferences. J Ind Rel 1981; 23; 240-249. (doi: 10.1177/002218568102300205)

26. Le Moual N, Kauffmann F, Eisen EA, Kennedy SM. The healthy worker effect in asthma: work may cause asthma, but asthma may also influence work. Am J Respir Crit Care Med 2008; 177: 4-10. (doi: 10.1164/rccm.200703-415PP)

\section{Authors:}

Sergey A. Maksimov - MD, Associate Professor, Researcher, Department Epidemiology of Cardiovascular Diseases, Research Institute for Complex Issues of Cardiovascular Diseases, Siberian Branch of Russian Academy of Medical Sciences, Kemerovo, Russia;

Galina V. Artamonova - MD, Full Doctor, Professor, Vice Director on Research, Research Institute for Complex Issues of Cardiovascular Diseases, Siberian Branch of Russian Academy of Medical Sciences, Kemerovo, Russia. 